\title{
Support of Paracoccidioides brasiliensis multiplication by human monocytes or macrophages: inhibition by activated phagocytes
}

\author{
MAURA MOSCARDI-BACCHI* $\dagger$, E. BRUMMER $\dagger \ddagger \S$ and D. A. STEVENS $†$ \\ * Faculdade de Medicina, University of Estadual Paulista, Botucatu, Brazil, $†$ Division of Infectious Diseases, \\ Department of Medicine, Santa Clara Valley Medical Centre and California Institute for Medical Research, 751 South \\ Bascom Avenue, San José, CA 95128 and $\$$ Division of Infectious Diseases and Geographic Medicine, Department \\ of Medicine, Stanford University Medical School, Stanford, CA 94305, USA
}

\begin{abstract}
Summary. The interaction of human monocytes or monocyte-derived macrophages and yeast-form Paracoccidioides brasiliensis was studied in vitro. Yeast cells were readily ingested by adherent monocytes or macrophages. Multiplication of $P$. brasiliensis, measured by growth as colony forming units (cfu) on a supplemented medium with good plating efficiency, was greater in monocyte co-cultures compared to the number of cfu obtained from complete tissue-culture medium (CTCM). Multiplication increased with time in macrophage cocultures, e.g., from two-six-fold in $24 \mathrm{~h}$ to nine-fold in $72 \mathrm{~h}$. Microscopic observations indicated that ingested yeast cells multiplied inside macrophages. When monocytes were treated with supernate cytokines (CK) from concanavalin-A-stimulated mononuclear cells, then co-cultured with $P$. brasiliensis, multiplication was significantly inhibited compared with control monocyte co-cultures. Treatment of macrophages-derived from monocytes by culture in vitro for 3 days - for a further 3 days with CK resulted in maximal inhibition of multiplication over the subsequent $72 \mathrm{~h}$. Similarly, when monocyte-derived macrophages (after culture for 7 days) were treated for 3 days with recombinant human $\gamma$-interferon (IFN; $300 \mathrm{U} / \mathrm{ml}$ ) or CK they restricted multiplication of P. brasiliensis by $65 \%$ and $95 \%$, respectively, compared with control macrophages. Antibody to IFN abrogated the effect of IFN or CK treatment. These findings show that ingested $P$. brasiliensis can multiply in human monocytes or macrophages and that this multiplication can be restricted by activated monocytes or macrophages.
\end{abstract}

\section{Introduction}

The causative agent of paracoccidioidomycosis, the most common systemic mycosis in Central and South America, is Paracoccidioides brasiliensis. ${ }^{1}$ This thermally dimorphic fungal pathogen in the saprophytic phase causes natural infections by inhalation of conidia or mycelial elements. Histological studies show that conidia convert to the parasitic yeast form in the lungs of mice within hours. ${ }^{2}$ Recently it was reported that ingested yeast-form $P$. brasiliensis readily multiplies inside murine alveolar or peritoneal macrophages; however, if macrophages were activated, multiplication was restricted and yeast cells were killed. $^{3}$

Immunological ${ }^{4,5}$ and histological ${ }^{6,7}$ studies relevant to effector-fungus interaction have been made in human paracoccidioidomycosis. Although $P$. brasiliensis was studied in biopsy tissue by transmission electronmicroscopy and yeast cells were demonstrated

Received 19 April 1993; revised version accepted 22 July 1993. $\S$ Correspondence should be sent to Dr E. Brummer. inside macrophages, ${ }^{6}$ histological techniques were not capable of following sequential events during the interaction of $P$. brasiliensis and human macrophages. The role of monocytes and tissue macrophages in the pathogenesis of, or resistance to, $P$. brasiliensis infection has not yet been defined.

The purpose of the present study was to measure the effect of normal monocytes or monocyte-derived macrophages on the multiplication of $P$. brasiliensis by sequential determination of numbers of colony forming units (cfu) in co-cultures and by microscopic observations. These results were compared with those from concurrent co-cultures of monocytes or macrophages previously exposed to cytokines (CK) or $\gamma$ interferon (IFN).

\section{Materials and methods}

Fungi

$P$. brasiliensis isolates LA (ATCC 32074), Gar (ATCC 76533) and Gra (ATCC 60855) were isolated from Colombian patients with paracoccidioido- 
mycosis and were supplied by Dr Angela Restrepo, CIB Laboratorios, Medellin. Yeast-form cultures were maintained on brain heart infusion (BHI) slopes at $35^{\circ} \mathrm{C}$ and transferred to fresh BHI slopes monthly. For inoculum preparations, modified McVeigh-Morton broth $(\mathrm{MMcVM})^{8}$ cultures were grown at $35^{\circ} \mathrm{C}$ on a gyratory shaker $(220 \mathrm{rpm})$ and subcultured weekly. The viability of yeast cells was determined by fluorescein diacetate-ethidium bromide (FDA-EB) vital staining and fluorescent microscopy. ${ }^{9}$ The viability of fungal units (one or more viable yeast cells/aggregate) was in the range $70-87 \%$. To determine the number of cfu, BHI or MMcVM agar supplemented with horse serum $4 \% \mathrm{v} / \mathrm{v}$ and MMcVM broth culture filtrate $5 \% \mathrm{v} / \mathrm{v}$ from 2-week-old yeast cultures was used. ${ }^{10}$ Plating efficiency with three different culture filtrates was $68.6 \mathrm{SD} 1.5 \%$ (BHI agar) and 58.0 SD $1.5 \%$ (MMcVM agar).

\section{Isolation of mononuclear cells}

In each series of experiments, blood was obtained from at least four different healthy adult donors who were skin-test-negative to paracoccidioidin. Peripheral blood mononuclear cells (PBMC; lymphocytes and monocytes) were separated from heparinised $(30 \mathrm{U} / \mathrm{ml})$ blood by density gradient centrifugation $(400 \mathrm{~g}, 40 \mathrm{~min})$ on Histopaque $(\mathrm{d}=1.077)$ (Sigma). Briefly, $4 \mathrm{ml}$ of heparinised blood was mixed over $4 \mathrm{ml}$ of phosphate-buffered saline (PBS), and layered over $3 \mathrm{ml}$ of Histopaque in a $15-\mathrm{ml}$ conical plastic centrifuge tube. After centrifugation at room temperature, the interface layer of mononuclear cells was collected, washed twice with RPMI-1640 tissue- culture medium (Gibco Laboratories, Grand Island, NY, USA), and counted with a haemocytometer. Mononuclear cells were suspended to $1 \times 10^{7}$ cells $/ \mathrm{ml}$ in CTCM. CTCM consisted of RPMI-1640, penicillin (100000 U/L), streptomycin $(100 \mathrm{mg} / \mathrm{L})$ and fresh autologous serum $15 \%$.

\section{Monocytes and monocyte-derived macrophages}

PBMC $\left(1 \times 10^{7} / \mathrm{ml}\right.$ in CTCM $)$ suspension was dispensed at $0.1 \mathrm{ml} /$ well in flat-bottomed microtest plate wells (Costar 3696; Costar Corporation, Cambridge, MA, USA). After incubation for $2 \mathrm{~h}$ at $37^{\circ} \mathrm{C}$ in air with $\mathrm{CO}_{2} 5 \%$, non-adherent cells were removed by aspiration and each well was rinsed once with RPMI1640. There were an estimated $(0 \cdot 1-0 \cdot 2) \times 10^{6}$ monocytes/well. Monocyte-derived macrophages were obtained by culture of monocytes in CTCM for 3-7 days with addition of fresh medium every 3 days.

\section{Cytokines}

PBMC at $3 \times 10^{6} / \mathrm{ml}$ in CTCM were incubated with or without concanavalin-A (Con-A) (Sigma) at $15 \mathrm{mg} / \mathrm{L}$ for $24 \mathrm{~h}$ at $37^{\circ} \mathrm{C}$ in air with $\mathrm{CO}_{2} 5 \%$. After incubation, cell-free cytokine (CK)-containing super- nates were obtained by centrifugation $(400 \mathrm{~g}, 10 \mathrm{~min})$, followed by filtration through $0 \cdot 4-\mu \mathrm{m}$ pore size filters. Supernates obtained in identical fashion from PBMC suspensions without Con-A were termed control CK. Small portions of $\mathrm{CK}$ were stored at $-70^{\circ} \mathrm{C}$. Human recombinant $\gamma$-interferon (IFN) ${ }^{11}$ and affinity columnpurified rabbit antibody to IFN were gifts from Genentech Inc., South San Francisco, CA, USA.

\section{Treatment of monolayers}

After adherence, monocytes were treated on the same day (or cultured for 3 or 7 days, then treated) with $0.1 \mathrm{ml}$ of Con-A-CK $40 \% \mathrm{v} / \mathrm{v}$ in CTCM, control CK $40 \% \mathrm{v} / \mathrm{v}$ or CTCM alone for 3 days. The macrophages treated with CTCM were defined as 6day and 10-day macrophages, respectively. Such monocyte-derived macrophages have been reported to have modified enzymic profiles. ${ }^{12}$ Con-A in Con-ACK was neutralised by the addition of $\alpha$-methyl-Dmannoside (Sigma) to a final concentration of $50 \mathrm{~mm}$.

\section{Challenge of monolayer with $P$. brasiliensis}

After the removal of supernates from treated monolayers, the monolayer fungicidal activity was tested by challenge with yeast-form $P$. brasiliensis $(0 \cdot 1 \mathrm{ml}$ of a suspension of 10000 or 20000 viable units $/ \mathrm{ml}$ in CTCM). Microscopic examination of the inoculum in four replicate tests showed that it consisted of $68 \mathrm{SD}$ $2 \%, 10$ SD $3 \%, 3$ SD $1 \%, 3$ SD $3 \%$ and 16 SD $3 \%$ of $1,2,3,4$ and $\geqslant 5$ cells/fungal unit, respectively. After co-culture for $4,24,48$ and $72 \mathrm{~h}$, cells were harvested with distilled water to lyse macrophages or monocytes. Complete removal of adherent cells was verified by microscopic examination of culture wells. Each culture and well washings were contained in 5 or $10 \mathrm{ml}$ of water. To determine fungicidal or fungistatic activity, the number of cfu of $P$. brasiliensis/culture was determined by plating $1 \mathrm{ml}$ of the 5 - or $10-\mathrm{ml}$ volume on supplemented BHI or MMcVM agar plates. When harvested material from co-cultures was pooled and cells were pelleted by centrifugation, microscopic examination showed that the pelleted cells consisted of 57 SD $7 \%, 14$ SD $8 \%, 5$ SD $2 \%, 4$ SD $1 \%$ and 20 SD $4 \%$ of $1,2,3,4$ and $\geqslant 5$ cells/fungal unit. There was no significant difference in this distribution when compared with control (CTCM) or inoculum samples. Inoculated plates were incubated at $35^{\circ} \mathrm{C}$ for 1 day then placed in sealed plastic bags to prevent drying. After 10 days at $35^{\circ} \mathrm{C}$, the number of $\mathrm{cfu} /$ plate was counted. The percentage inhibition of multiplication was determined by the formula: [1-(cfu of experimental culture/cfu of control culture) $] \times 100$.

\section{Transwell studies}

Seven-day macrophage monolayers were established in the lower chamber $(16 \mathrm{~mm}$ diameter $)$ of Transwell tissue-culture plates (Costar). This was 
done by incubating $0.5 \mathrm{ml}$ of a suspension of $5 \times 10^{6} \mathrm{PBMC} / \mathrm{ml}$ in CTCM for $2 \mathrm{~h}$, removal of nonadherent cells, then incubation for 7 days at $37^{\circ} \mathrm{C}$ in air with $\mathrm{CO}_{2} 5 \%$. Macrophages were then treated for another 3 days with CTCM. $P$. brasiliensis (Gar; $0 \cdot 2 \mathrm{ml}$ of 10000 viable fungal units $/ \mathrm{ml}$ in CTCM) was then cultured in the upper chamber $(6.5 \mathrm{~mm}$ diameter with a $0.4-\mu \mathrm{m}$ pore size membrane bottom) for 3 days, with $0.5 \mathrm{ml}$ of CTCM, or macrophage monolayer containing $0.5 \mathrm{ml}$ of CTCM, in the lower chamber. Positive controls consisted of a macrophage monolayer in direct contact with $P$. brasiliensis (no membrane present).

\section{Microscopic and phagocytosis studies}

Monocyte or macrophage monolayers were obtained by plating $0.25 \mathrm{ml}$ of a suspension of $2.5 \times 10^{6} \mathrm{PBMC} / \mathrm{ml}$ of $\mathrm{CTCM} /$ chamber of eightchambered Lab-Tek tissue-culture slides (Miles Scientific, Naperville, IL, USA). After removal of nonadherent cells, adherent cells were incubated at $37^{\circ} \mathrm{C}$ in air with $\mathrm{CO}_{2} 5 \%$ for 1 or 3 days with $0.25 \mathrm{ml}$ of CTCM or CK $40 \% \mathrm{v} / \mathrm{v}$ in CTCM. After treatment of monolayers, the supernates were aspirated, and cultures were rinsed with CTCM and challenged with $P$. brasiliensis in CTCM containing fresh human serum $25 \%$. The ratio of fungal units:macrophages was c. 1:2 for microscopy studies and 5:1 for phagocytosis determinations. Co-cultures were incubated for $4 \mathrm{~h}$ for phagocytosis and $4,24,48$ or $72 \mathrm{~h}$ in microscopy studies. Duplicate sets of cultures were aspirated, washed three times with PBS, air-dried, and stained with Diff-Quik stain (American Scientific Products, McGaw Park, IL, USA). Two hundred monocytes or macrophages with or without ingested $P$. brasiliensis were counted in each of duplicate monolayers.

\section{Statistical analysis}

Comparisons between groups were analysed by Student's $t$ test, with significance assumed to be $\mathrm{p}<0.05$. Variation is expressed as SD.

\section{Results}

\section{Effect of monocytes or 6-day macrophages on $P$. brasiliensis multiplication}

When $P$. brasiliensis isolates LA, Gar and Gra were cultured with CTCM alone there was generally no significant increase in cfu with time (table I). The exceptions are noted in table I. Compared with the number of cfu of LA in CTCM alone, a significantly greater number of isolate cfu were recovered from cocultures of isolate LA plus monocytes or 10-day macrophages at 24, 48 and $72 \mathrm{~h}$ (table I).

If monocytes and isolate LA were co-cultured for $144 \mathrm{~h}$, a 10 -fold increase in the number of cfu was recorded. This greater enhancement could have been due to lysis of infected monocyte-derived macrophages and, possibly, infection of other macrophages, or nutrient supplementation.

When 6-day macrophages were co-cultured with the Gar isolate, the number of cfu increased significantly after 24,48 and $72 \mathrm{~h}$ compared with the number of cfu in CTCM alone (table I).

The number of cfu of another isolate, Gra, increased significantly in co-cultures with 6-day or 10-day macrophages after 24,48 , and $72 \mathrm{~h}$ when compared with the number of $\mathrm{cfu}$ in CTCM alone (table I). Results from the three experiments with three isolates shown in table I indicate that monocytes, 6-day and 10-day monocyte-derived macrophages each supported the multiplication of $P$. brasiliensis isolates in co-cultures compared with multiplication in CTCM alone.

\section{Contact requirement for macrophage enhancement of P. brasiliensis}

When $P$. brasiliensis (Gar) was separated from 10 day macrophage monolayers by the Transwell membrane, multiplication was not enhanced. For example, after culture for 3 days the numbers of cfu of isolate Gar were not significantly different when separated from CTCM or the macrophage monolayer, i.e. 1410 SD 280 and 1260 SD $160(n=4)$, respectively. In contrast, isolate Gar in contact with macrophages had enhanced multiplication $(\mathrm{p}<0.001)$, i.e., $4540 \mathrm{SD}$ $680 \mathrm{cfu} /$ well.

\section{Effect of lymphocytes on P. brasiliensis multiplication}

After two cycles of adherence ( 2 and $48 \mathrm{~h}$ ), nonadherent PBMC were primarily small lymphocytes (PBL). When PBL $\left(5 \times 10^{5} /\right.$ well $)$ were co-cultured with $P$. brasiliensis (Gar; $10^{3} \mathrm{cfu} /$ well), multiplication of isolate Gar was not increased compared with the number of cfu in CTCM alone. After culture for 3 days the numbers of cfu in CTCM and PBL co-cultures were not significantly different, i.e., 985 SD 60 and 990 SD $90(n=4)$, respectively.

\section{Effect of CK treatment of monocytes on multiplication of $P$. brasiliensis}

After adherence, monocytes were treated the same day for $24 \mathrm{~h}$ with CK or CTCM, then co-cultured with the isolate LA. CK-treated monocytes inhibited LA multiplication compared with macrophages exposed to CTCM. There was no early (4-h) inhibition but maximal inhibition at $24 \mathrm{~h}(55 \%, \mathrm{p}<0.01)$ followed by a decline in inhibition at $48 \mathrm{~h}(35 \%, \mathrm{p}<0.05)$ compared with the numbers of cfu of the LA isolate in CTCM at these times (data not shown).

\section{Effect of CK treatment on 3-day monocyte-derived macrophages}

When 3-day monocyte-derived macrophages were treated for 3 days with $\mathrm{CK}$ and then co-cultured with 
Table I. Effect of monocytes and monocyte-derived macrophages on multiplication of $P$. brasiliensis isolates

\begin{tabular}{|c|c|c|c|c|}
\hline \multirow{2}{*}{ Isolate } & \multicolumn{4}{|c|}{ Mean (SD) cfu $\times 10^{3}(n=4)$ at } \\
\hline & $4 \mathrm{~h}$ & $24 \mathrm{~h}$ & $48 \mathrm{~h}$ & $72 \mathrm{~h}$ \\
\hline \multicolumn{5}{|l|}{ LA } \\
\hline CTCM & $0 \cdot 3(0 \cdot 1)$ & $0 \cdot 4(0 \cdot 1)$ & $0.5(0.2)$ & $\ldots$ \\
\hline Monocytes & $0 \cdot 3(0 \cdot 1)$ & $0.9(0.2) \dagger$ & $1.7(0.3) \ddagger$ & $\ldots$ \\
\hline CTCM & $1 \cdot 1(0 \cdot 2)$ & $1 \cdot 2(0 \cdot 2)$ & $1.7(0.3)^{*}$ & $2 \cdot 9(0.4)^{*}$ \\
\hline $\begin{array}{l}\text { Macrophages } \\
\text { (10 day) }\end{array}$ & $2 \cdot 0(0 \cdot 2) \dagger$ & $3 \cdot 3(0 \cdot 4) \ddagger$ & $3.9(0 \cdot 7) \ddagger$ & $5 \cdot 5(0 \cdot 7) \ddagger$ \\
\hline \multicolumn{5}{|l|}{ Gar } \\
\hline CTCM & $0 \cdot 6(0 \cdot 1)$ & $0.6(0 \cdot 1)$ & $0.7(0 \cdot 1)$ & $0.3(0 \cdot 1)$ \\
\hline $\begin{array}{l}\text { Macrophages } \\
\text { (6 day) }\end{array}$ & $1.2(0.2) \dagger$ & $1.0(0.2) \dagger$ & $2 \cdot 7(0 \cdot 7) \ddagger$ & $1.9(0.1)$ \\
\hline \multicolumn{5}{|l|}{ Gra } \\
\hline CTCM & $0 \cdot 3(0 \cdot 1)$ & $0 \cdot 3(0 \cdot 2)$ & $0.7(0.1)^{*}$ & $0.5(0.3)$ \\
\hline $\begin{array}{l}\text { Macrophages } \\
\text { (6 day) }\end{array}$ & $0.8(0.1) \dagger$ & $0.9(0.2) \dagger$ & $1 \cdot 3(0 \cdot 3) \dagger$ & $1 \cdot 2(0 \cdot 2) \dagger$ \\
\hline CTCM & $\ldots$ & $0 \cdot 4(0 \cdot 1)$ & $1.4(0 \cdot 1)^{*}$ & $0.5(0.2)$ \\
\hline $\begin{array}{l}\text { Macrophages } \\
\text { (10 day) }\end{array}$ & $\cdots$ & $3 \cdot 2(0 \cdot 2) \ddagger$ & $3.8(0 \cdot 2) \ddagger$ & $5 \cdot 3(0 \cdot 7)$ \\
\hline
\end{tabular}

* Significant $(\mathrm{p}<0.01)$ compared with number of cfu in CTCM at $4 \mathrm{~h}$

Significant increase in co-culture cfu number compared with cfu number in CTCM alone; $+\mathrm{p}<0.01, \pm \mathrm{p}<0.001$

Table II. Inhibition of $P$. brasiliensis multiplication by cytokine-treated monocytederived macrophages

\begin{tabular}{|c|c|c|c|c|}
\hline \multirow{2}{*}{ Isolate Gar with } & \multicolumn{4}{|c|}{ Mean (SD) cfu $\times 10^{3}(\mathrm{n}=4)$ at } \\
\hline & $4 \mathrm{~h}$ & $24 \mathrm{~h}$ & $48 \mathrm{~h}$ & $72 \mathrm{~h}$ \\
\hline CTCM & $0 \cdot 6(0 \cdot 1)$ & $0.8(0 \cdot 1)$ & $0.7(0.3)$ & $0 \cdot 3(0 \cdot 1)$ \\
\hline $\begin{array}{l}\text { Macrophages } \\
(3 \text { day + CTCM) }\end{array}$ & $1 \cdot 2(0 \cdot 2)$ & $1 \cdot 1(0 \cdot 3)$ & $2 \cdot 8(0 \cdot 7)$ & $1.9(0 \cdot 1)$ \\
\hline $\begin{array}{l}\text { Macrophages } \\
(3 \text { day }+ \text { CK })\end{array}$ & $0 \cdot 6(0 \cdot 1)^{*}$ & $0 \cdot 8(0 \cdot 2)$ & $1 \cdot 1(0 \cdot 3)^{*}$ & $0 \cdot 1(0 \cdot 1) \dagger$ \\
\hline СТCM & $\ldots$ & $0.4(0 \cdot 1)$ & $0.9(0 \cdot 1)$ & $0.5(0 \cdot 3)$ \\
\hline $\begin{array}{l}\text { Macrophages } \\
(7 \text { day + CTCM })\end{array}$ & $\cdots$ & $3 \cdot 0(0 \cdot 2)$ & $3 \cdot 9(0 \cdot 2)$ & $5 \cdot 3(0 \cdot 5)$ \\
\hline $\begin{array}{l}\text { Macrophages } \\
(7 \text { day }+\mathrm{CK})\end{array}$ & $\cdots$ & $0.5(0 \cdot 1) \dagger$ & $3 \cdot 0(0 \cdot 1) \dagger$ & $0.3(0 \cdot 1) \dagger$ \\
\hline
\end{tabular}

There were significantly fewer cfu in CK-treated macrophage co-cultures than in control CTCM macrophage co-cultures; ${ }^{*} \mathrm{p}<0.01, \dagger \mathrm{p}<0.001$.

isolates Gar or Gra, they inhibited the multiplication of these isolates compared with multiplication in macrophages exposed only to CTCM. Representative results from four experiments are given in table II. Compared with multiplication in macrophages treated with CTCM, multiplication of isolate Gar in CKtreated macrophages was inhibited at $4 \mathrm{~h}$. The inhibition was less at $24 \mathrm{~h}$, then increased with further time, e.g., at 48 and $72 \mathrm{~h}$ (table II).

\section{Effect of CK treatment on 7-day monocyte-derived macrophages}

Seven-day macrophages were treated for 3 days with CK, control CK or CTCM (controls), then co-cultured with isolate Gar for selected periods. CK-treated macrophages were also able to restrict the multiplication of isolate Gar compared with control macrophages after 24, 48 and $72 \mathrm{~h}$ (table II). When antibody to IFN was present during CK treatment of macrophage monolayers, these macrophages were not able to inhibit the multiplication of isolate Gar; on the contrary they supported multiplication of isolate Gar better than control macrophages, at $48 \mathrm{~h}: 5220 \mathrm{SD}$ 880 versus 3870 SD $200 \mathrm{cfu}(\mathrm{n}=4)$ (data not shown).

When isolate LA was used, CK-treated macrophages also significantly $(p<0.01)$ inhibited multiplication of LA compared with macrophage controls, after 24, 48 and $72 \mathrm{~h}$ (data not shown).

Treatment with control CK (supernates from nonstimulated PBMC cultures) did not enable macrophages to inhibit multiplication of isolate Gar. There 


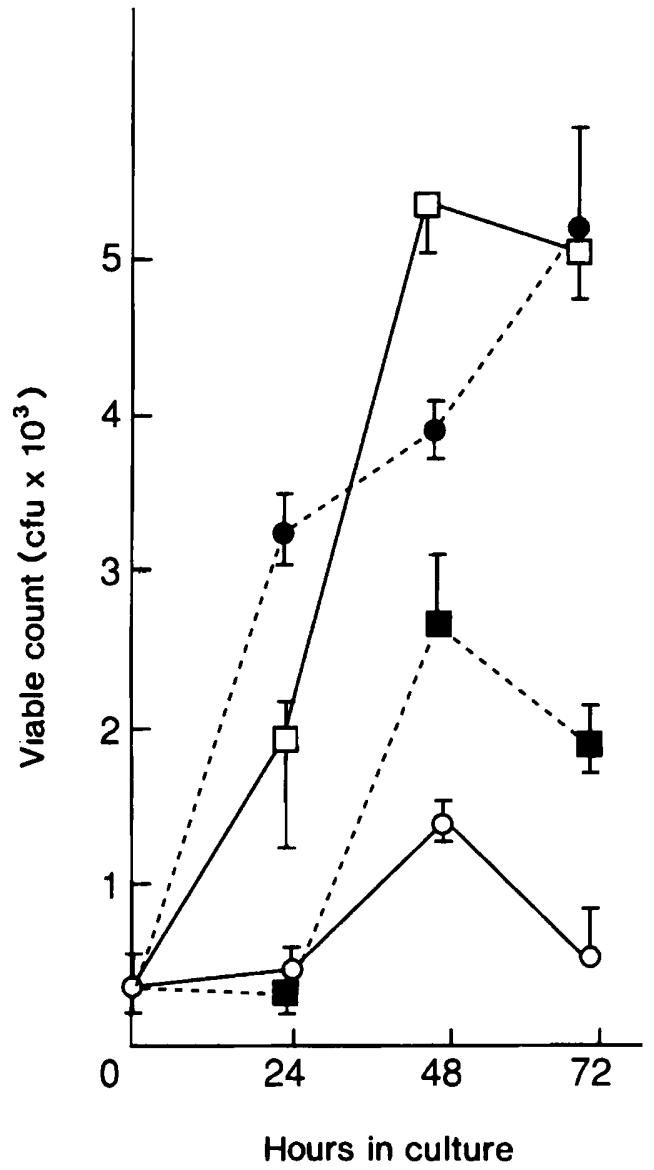

Figure. Inhibition of $P$. brasiliensis multiplication by IFN-treated 7 day monocyte-derived macrophages: mean cfu and SD of quadruplicate cultures of isolate Gar in CTCM alone $(O)$ and in 7-day macrophages treated for 3 days with IFN (ש), IFN plus antibody to IFN ( $\square$ ), or with CTCM (controls); denote various times of culture in a single experiment.

was no significant difference between multiplication in macrophages exposed to control CK or to CTCM (data not shown).

\section{Effect of IFN treatment on 7-day monocyte-derived macrophages}

IFN-treated 7-day macrophages were able to significantly restrict the multiplication of the Gar isolate after 24,48 and $72 \mathrm{~h}$ compared with multiplication in CTCM control macrophages (figure). If antibody to IFN (enough to neutralise $600 \mathrm{IFN} \mathrm{U/ml)} \mathrm{was} \mathrm{added}$ during IFN treatment of macrophages, the macrophages were not able to significantly inhibit multiplication of $P$. brasiliensis at 24,48 or $72 \mathrm{~h}$ compared with CTCM control macrophages (figure).

\section{Phagocytosis}

Monocyte or 6-day monocyte-derived macrophages were incubated with $P$. brasiliensis yeast cells at a yeast cell:phagocyte ratio of $5: 1$ for $4 \mathrm{~h}$. After washing away non-phagocytosed fungi, the monolayers were air-dried and stained. The percentage of monocytes treated for 1 day with CTCM that ingested yeast cells was $80.0 \mathrm{SD} 4.9 \%$. The percentage of 6-day monocyte- derived macrophages exposed to $\mathrm{CTCM}$ alone that ingested yeast cells was $73.0 \mathrm{SD} 7.0 \%$. These results were not different from those obtained with CKtreated monocytes or monocyte-derived macrophages (data not shown).

\section{Microscopy studies}

For microscopy studies, a yeast cell: phagocyte ratio of $1: 2$ was used to follow better intracellular events with time. The best evidence for intracellular multiplication of $P$. brasiliensis was obtained by comparing yeast cells $4 \mathrm{~h}$ after ingestion and $P$. brasiliensis in macrophages 24 and $48 \mathrm{~h}$ later. The best results were seen with the larger 7-day monocyte-derived macrophages. $P$. brasiliensis $24 \mathrm{~h}$ after ingestion by macrophages showed development of mother cells with buds. After culture for $48 \mathrm{~h}$, intracellular yeast cells consisted primarily of budding mother cells or small detached daughter cells (data not shown).

\section{Discussion}

This report presents evidence for the first time that $P$. brasiliensis multiplication is supported by monocyte, 6-day macrophage, and especially 10 -day macrophage co-cultures when compared with $P$. brasiliensis in CTCM alone. By contrast, $P$. brasiliensis multiplication was not supported by co-culture with a nonphagocytic cell type, i.e., lymphocytes. It was also found that contact between macrophages and $P$. brasiliensis was required for support of $P$. brasiliensis multiplication by macrophages. Moreover, microscopy studies indicated that ingested $P$. brasiliensis multiplied inside macrophages. Although the size and morphology of macrophages changed with time in culture and possibly a decrease in numbers/well occurred, the low inoculum:macrophage ratio $(1: 100)$ minimised the effect of these variations. These findings are similar to those reported previously for $P$. brasiliensis multiplication in murine peritoneal or alveolar macrophages. ${ }^{3}$

Human macrophages also support the intracellular multiplication of Histoplasma capsulatum, another thermally dimorphic fungal pathogen, ${ }^{13}$ although $H$. capsulatum also multiplies well in CTCM. ${ }^{14}$ On the other hand, the thermally dimorphic fungal pathogen Blastomyces dermatitidis did not exhibit enhanced multiplication in co-cultures with human monocytes or macrophages; instead, multiplication was inhibited compared to inoculation in CTCM alone. ${ }^{15}$

Human 3- or 7-day macrophages treated for 3 days with $\mathrm{CK}$ or IFN were modulated so that they restricted the multiplication of $P$. brasiliensis in long-term cultures. Moreover, this modulation by IFN or CK could be inhibited by the presence of antibody to IFN. Abrogation of the ability of $\mathrm{CK}$ to activate macrophages by anti-IFN antibody indicates that IFN was the major cytokine in supernates responsible for 
macrophage activation and other cytokines, e.g., IL-2 etc., had an insignificant effect. However, treated macrophages were not able to reduce $P$. brasiliensis inoculum cfu consistently, either in short- (4-h) or long-term assays. However, it should be noted that inhibition of $P$. brasiliensis multiplication by activated macrophages could represent the killing of some yeast cells and growth of remaining viable cells.

The lack of demonstrable fungicidal activity of treated human macrophages for $P$. brasiliensis is in sharp contrast to that reported for activated murine peritoneal or alveolar macrophages. ${ }^{3}$ This could be due to the well documented difference between murine and human macrophages relative to induction of an L-arginine-dependent nitric oxide-producing mechanism. Whether human resident tissue or alveolar macrophages, ${ }^{16,17}$ in contrast to monocyte-derived macrophages, can be activated to kill $P$. brasiliensis remains to be determined.

It has been shown that $P$. brasiliensis requires

\section{References}

1. Restrepo A, Greer DL, Vasconellos M. Paracoccidioidomycosis: a review. Rev Med Vet Mycol 1973; 8: 97-123.

2. McEwen JG, Bedoya V, Patino MM, Salazar ME, Restrepo A. Experimental murine paracoccidioidomycosis induced by the inhalation of conidia. J Med Vet Mycol 1987; 25: $165-175$.

3. Brummer E, Hanson LH, Restrepo A, Stevens DA. Intracellular multiplication of Paracoccidioides brasiliensis in macrophages: killing and restriction of multiplication by activated macrophages. Infect Immun 1989; 57: 2289-2294.

4. Musatti CC, Reskallah MT, Mendes E, Mendes NF. In vivo and in vitro evaluation of cell-mediated immunity in patients with paracoccidioidomycosis. Cell Immunol 1976; 24: $365-378$.

5. Restrepo A, Restrepo M, de Restrepo F, Aristizabel LH, Moncada $L H$, Vélez H. Immune responses in paracoccidioidomycosis. A controlled study of 16 patients before and after treatment. Sabouraudia 1978; 16: 151-163.

6. Furtado JS, De Brito T, Freymuller E. The structure and reproduction of Paracoccidioides brasiliensis in human tissues. Sabouraudia 1967; 5: 226-229.

7. Moscardi-Bacchi M, Soares A, Mendes R, Marques S, Franco $M$. In situ localization of $T$ lymphocyte subsets in human paracoccidioidomycosis. J Med Vet Mycol 1989; 27: $149-158$.

8. Restrepo A, Jiménez BE. Growth of Paracoccidioides brasiliensis yeast phase in a chemically defined medium. $J$ Clin Microbiol 1980; 12: 279-281.

9. Restrepo A, Cano LE, deBedout C, Brummer E, Stevens DA. Comparison of various techniques for determining viability of Paracoccidioides brasiliensis yeast-form cells. $J$ Clin Microbiol 1982; 16: 209-211.

10. Castaneda E, Brummer E, Perlman AM, McEwen JG, Stevens DA. A culture medium for Paracoccidioides brasiliensis with high plating efficiency, and the effect of siderophores. J Med Vet Mycol 1988; 26: 351-358. siderophores and a source of utilisable iron for vigorous growth. ${ }^{10}$ RPMI-1640 does not contain a source of iron, and the only source of iron in CTCM is serum transferrin. We have shown that the permissive multiplication of $P$. brasiliensis in non-activated macrophages can be abrogated by desferoxamine $(15 \mu \mathrm{M})$. Fungistasis by activated macrophages was abrogated by iron-saturated transferrin $(6 \mathrm{~g} / \mathrm{L})$ but not by apotransferrin (data not shown). We propose that a similar mechanism is operative in activated human macrophages. This is consistent with the microbiostatic mechanism described by others, i.e., the down-regulation of transferrin receptor expression on activated macrophages, ${ }^{18,19}$ followed by intracellular iron deprivation. Such a scenario has been well documented by Byrd and Horwitz ${ }^{18}$ with the inhibition of intracellular multiplication of Legionella pneumophila by activated monocytes.

This work was partially supported by a FAPESP Brazil scholarship to M.M-B.

11. Gray PW, Leung DW, Pennica D et al. Expression of human immune interferon cDNA in $E$. coli and monkey cells. Nature 1982; 295: 503-508.

12. Musson RA, Shafran H, Henson PM. Intracellular levels and stimulated release of lysosomal enzymes from human peripheral blood monocytes and monocyte-derived macrophages. J Reticuloendothel Soc 1980; 28: 249-264.

13. Brummer E, Kurita N, Yoshida S, Nishimura K, Miyaji M. Killing of Histoplasma capsulatum by $\gamma$-interferon activated human monocyte-derived macrophages: evidence for a superoxide anion-dependent mechanism. $J$ Med Microbiol $1991 ; 35: 29-34$

14. Brummer E, Kurita N, Yoshida S, Nishimura K, Miyaji M. Fungistatic activity of human neutrophils against Histoplasma capsulatum : correlation with phagocytosis. J Infect Dis $1991 ; 164$ : 158-162.

15. Brummer E, Stevens DA. Opposite effects of human monocytes, macrophages, and polymorphonuclear neutrophils on replication of Blastomyces dermatitidis in vitro. Infect Immun 1982; 36: 297-303.

16. Catterall JR, Black CM, Leventhal JP, Rizk NW, Wachtel JS, Remington JS. Nonoxidative microbicidal activity in normal human alveolar and peritoneal macrophages. Infect Immun 1987; 55: 1635-1640.

17. Nguyen B-YT, Peterson PK, Verbrugh HA, Quie PG, Hoidal JR. Differences in phagocytosis and killing by alveolar macrophages from humans, rabbits, rats, and hamsters. Infect Immun 1982; 36: 504-509.

18. Byrd TF, Horwitz MA. Interferon gamma-activated human monocytes downregulate transferrin receptors and inhibit the intracellular multiplication of Legionella pneumophila by limiting the availability of iron. $J$ Clin Invest $1989 ; \mathbf{8 3}$ : 1457-1465.

19. Hamilton TA, Gray PW, Adams DO. Expression of the transferrin receptor on murine peritoneal macrophages is modulated by in vitro treatment with interferon-gamma. Cell Immunol 1984; 89: 478-488. 